\title{
Crystallite-size-dependent characteristics of porous silicon
}

\author{
S V BHORASKAR, TEJASHREE BHAVE and T A RAILKAR \\ Department of Physics, University of Poona, Pune 411 007, India
}

\begin{abstract}
Porous silicon prepared with anodic currents of 5 to $30 \mathrm{~mA} / \mathrm{cm}^{2}$ are characterized for structural and electronic properties of surface using photoluminescence, grazing angle $\mathrm{X}$-ray diffraction, photoconductivity, thermally stimulated exo electron emission and work function measurements. The observed results indicate that with increasing porosity the crystallite size decreases and the amount of silicon hydride and oxide-type species increases, exhibiting a tendency similar to that of hydrogenated amorphous silicon and hydrogenated microcrystalline silicon. Free-standing powder of porous silicon, characterized by bright photoluminescence at $730 \mathrm{~nm}$, showed crystallites of nanometre dimensions under the transmission electron microscope.
\end{abstract}

Keywords. Porous silicon; crystallite size dependence.

\section{Introduction}

On account of its visible light emission at room temperature, much interest has recently been shown in silicon nanostructures fabricated by electrochemical anodization, often called (Canham 1990) porous silicon (PS), and many experiments have been done in order to clarify the light-emitting mechanism. Many papers (Lehmann and Gosele 1991; Fathauer et al 1992; Ochiai et al 1992; Prokes et al 1992; Tsu et al 1992; Xu et al 1992; Noguchi and Sucmune 1993) from all over the world, have confirmed the emission of visible light following optical excitation of porous silicon prepared by different methods. However, there are controversial arguments put forward to explain the phenomenon of light emission. Canham (1990) first proposed that the photoluminescence originates from silicon columns due to quantum size effects. Various experiments have shown that quantum crystallites of around $20-50 \AA$ exist after the formation of porous silicon (Lehmann and Gosele 1991; Bellet et al 1992) and are also responsible for the photoluminescence. Another explanation which is also gaining support (Perez et al 1992; Vasquez et al 1992) considers the formation of hydrogenated amorphous silicon $(\mathrm{a}-\mathrm{Si}: \mathrm{H})$ on the surface of porous silicon. A controversial model based on the formation of siloxene molecules on the surface has also been put forward (Brandt et al 1992; Stutzmann et al 1993). Till now, therefore, the basic question of the mechanism of luminescence in PS remains open and a satisfactory model which can explain all the basic experimental phenomena of the PS layer has not yet been formulated.

In this paper we have characterized electrochemicall: prepared porous silicon by measuring its structural and electronic properties as a function of crystallite size.

Our grazing angle X-ray diffraction studies indicate the presence of nanocrystallites on the surface of PS. Photoconductivity and electronic work function measurements also indirectly support the reduction in crystallite dimension and behaviour similar to hydrogenated microcrystalline silicon (Matsuda et al 1983) (u-Si:H) films. The structural defects in porous silicon, resulting in gap states at the surface, have been monitored using the method of thermally stimulated exoelectron emission (TSEE) 
measurement, which has been established (Railkar et al 1992) as a sensitive tool for detection of surface states. From these measurements it seems highly probable that the pores are filled with silicon oxide or silicon hydride complexes. This supports the conclusions drawn from photoconductivity and work function measurements.

\section{Experimental}

Porous silicon was prepared by anodic etching of p-type, 285- $\mu \mathrm{m}$-thick $\mathrm{Si}(111)$ wafers with resistivity of $10 \Omega \mathrm{cm}$. Ohmic contacts were established on one of the surfaces of $15 \mathrm{~mm} \times 12 \mathrm{~mm}$ rectangular pieces of the wafer. Synthesis of PS was performed in an $\mathrm{HF}(48 \%)$-based solution with ethanol (1:1), with current densities ranging between 5 and $30 \mathrm{~mA} / \mathrm{cm}^{2}$, for 20 to $30 \mathrm{~min}$. Graphite was used as the cathode material. The resulting PS was reddish-brown. Free-standing PS powder was separated from the $\mathrm{Si}$ substrate by reducing the electrolytic concentration to $\sim 1 \mathrm{wt} \%$ aqueous $\mathrm{HF}$ and then passing a high current $\left(\sim 200 \mathrm{~mA} / \mathrm{cm}^{2}\right)$ for about $10 \mathrm{sec}$.

The photoluminescence (PL) set-up included a $\mathrm{He}-\mathrm{Ne}$ or argon ion laser, monochromator grating with spacing of 600 lines $/ \mathrm{mm}$, a silicon detector and an IEEE 488 interface. All the PL measurements were carried out at room temperature. The $I-V$ characteristics were measured by establishing planer ohmic contacts on the surface of PS using two-probe method and subsequent photoconductivity was measured by illuminating the surface with a $500 \mathrm{~W}$ Sungun. Grazing angle X-ray diffraction (XRD) measurements were carried out using a Rigaku (Rotalex RV 200 B) Diffractometer at a grazing angle of $0.5^{\circ}$. The technique of TSEE consists in monitoring the electron current emitted from the defect centres at the surface of the sample which is thermally stimulated at a linear rate, after cooling it to a desired low temperature. The electrons, localized in the defect states at the surface, are emitted at characteristic temperatures. The experimental details are explained in our earlier publication (Railkar et al 1992). The work function of the PS surface was determined using the retarding field technique (experimental details described elsewhere, Rajopadhye and Bhoraskar 1986), in ultrahigh-vacuum conditions (pressure $\leqslant 10^{-9}$ torr) using a low-energy $(0-15 \mathrm{eV})$ electron beam. Gold was used as a reference sample. The accuracy in the value of the work function was about $\pm 0 \cdot 10 \mathrm{eV}$.

For TEM measurements, the free-standing powder of PS was dispersed ultrasonically in isopropyl alcohol for several seconds. A drop of this suspension was then placed on a TEM specimen grid. Samples thus prepared were dried and then examined with a transmission electron microscope (Model $1200 \mathrm{Ex}$, Jeol, Japan, $130 \mathrm{kV}$ ) in both diffraction and bright-field mode. The lattice parameter calibration with gold film showed the accuracy of the measurements to be better than $\pm 1 \%$.

\section{Results and discussion}

The porous silicon samples prepared at different current densities, between $5 \mathrm{~mA}$ and $30 \mathrm{~mA} / \mathrm{cm}^{2}$, showed a broad room-temperature PL peak centred around $880 \mathrm{~nm}$ when excited with $\mathrm{He}-\mathrm{Ne}$ laser and at $750 \mathrm{~nm}$ when excited by $\mathrm{Ar}$ ion laser as shown in figure 1 . The grazing angle $X$-ray diffraction pattern recorded at a glancing angle of $0.5^{\circ}$ is shown in figure $2 \mathrm{a}$ for PS prepared at an anodic current density of $25 \mathrm{~mA} / \mathrm{cm}^{2}$. 


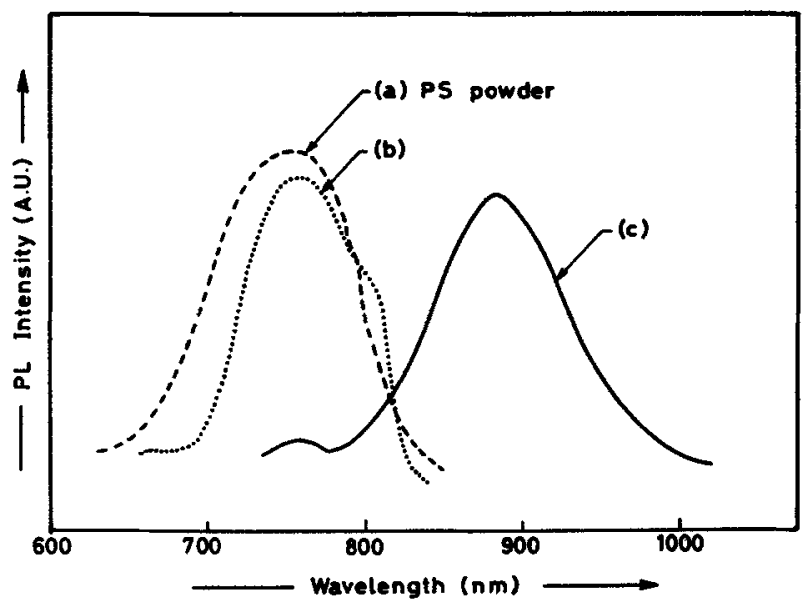

Figure 1. Photoluminescence spectra of porous silicon: (a) free-standing powder, excited with Ar ion laser (514 nm); (b) prepared with anodic currents from 5 to $25 \mathrm{~mA}$ and excited with $\mathrm{Ar}$ ion laser $(514 \mathrm{~nm})$; and (c) prepared with anodic currents from 5 to $25 \mathrm{~mA}$ and excited with $\mathrm{He}-\mathrm{Ne}$ ion laser $(632 \mathrm{~nm})$.
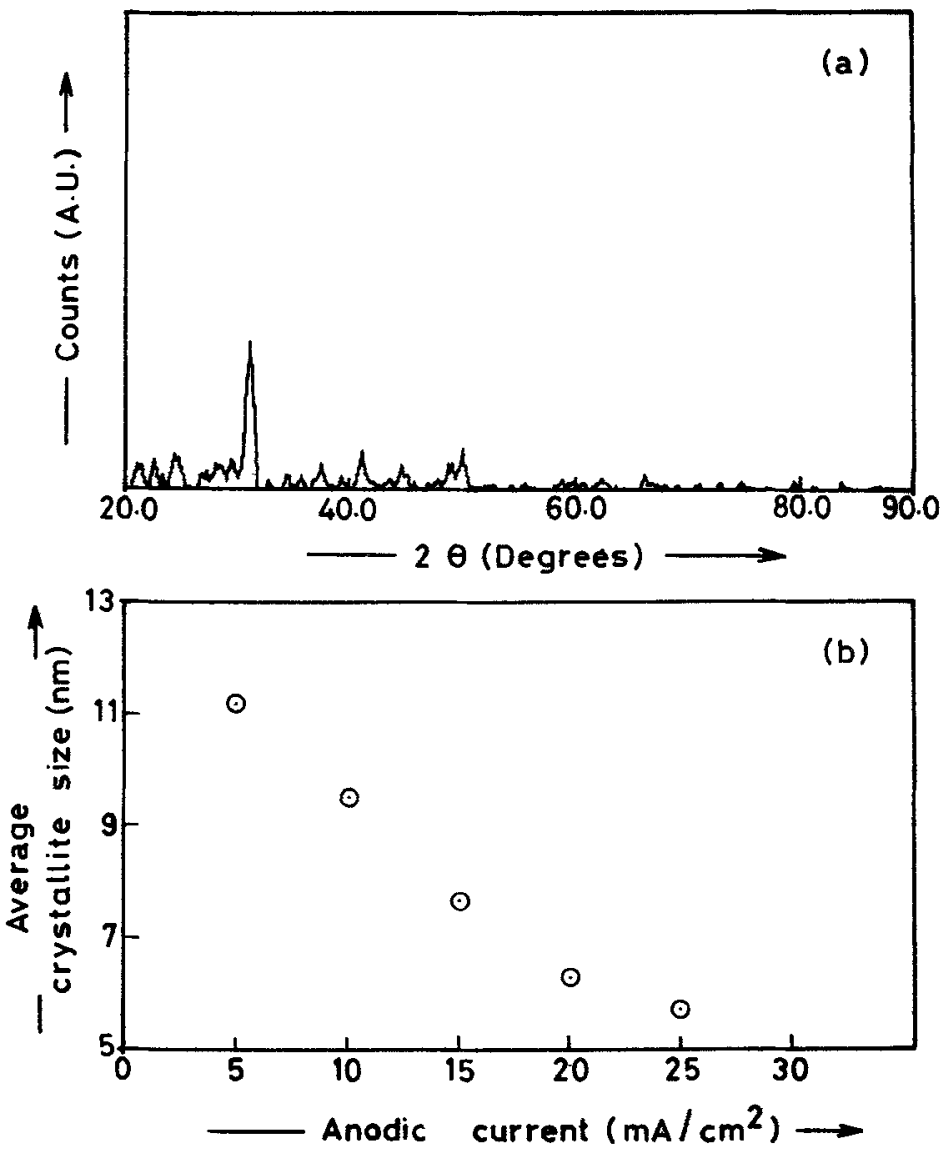

Figure 2 (a) Grazing angle X-ray diffraction pattern of porous silicon $\left(20 \mathrm{~mA} / \mathrm{cm}^{2}\right)$ recorded at a glancing angle of $0 \cdot 5^{\circ}$, (b) variation of crystalline size with anodic current densities. 
The average grain size (crystallite size) corresponding to the average diameter $(t)$ of the crystallite columns was determined using the Debye - Scherrer formula

$$
t=0.9 \lambda / \beta_{1 / 2} \cos \theta \text {, }
$$

where $\beta_{1 / 2}$ is the full width at half maximum for the diffraction peak, $\theta$ the diffraction angle, and $\lambda$ was $1.54 \AA$ for the $\mathrm{CuK}_{\alpha}$ line.

The crystallite size deduced from these measurements showed a variation of $11.38 \mathrm{~nm}$ to $5.72 \mathrm{~nm}$ as the current density was increased from $5 \mathrm{~mA} / \mathrm{cm}^{2}$ to $25 \mathrm{~mA} / \mathrm{cm}^{2}$ (figure $2 \mathrm{~b}$ ). The decrease in the average crystallite size also indicates an increase in the porosity, as is evident in previous reports by Yon et al (1987), who have estimated the porosity by gravimetric measurement. If we assume the nature of the porous silicon to be consisting of filamentary type of arrays giving rise to quantum confinement, as is mostly accepted, the thickness of the porous layer and therefore the columnar length is seen to be less affected by the current density. The average thickness of the layer of PS was measured using the scanning electron microscopic image and was found to be about $5-10 \mu \mathrm{m}$. Here it is worth noting that there is no blue shift in the PL spectra for the PS samples prepared for these currents (figure 1). Similar results have also been observed by others (Kanemitsa et al 1993), wherein it has been inferred that the PL spectrum scarcely depends on the size of Si crystallite. The shift in the wavelength with respect to the excitation energy of the incident laser however supports the quantum confinement.

Electrical resistivity measurements with these samples were approximated by the planar $I-V$ characteristics. The surface resistivity was seen to increase as seen in figure 3 for PS samples prepared by variation of anodic current from $5 \mathrm{~mA} / \mathrm{cm}^{2}$ to $25 \mathrm{~mA} / \mathrm{cm}^{2}$. The photoconductivity showed very interesting behaviour and remained approximately identical in all the PS samples prepared with different current densities. The behaviour was also identical to that obtained with a virgin crystalline silicon sample. The gain in the photocurrent, defined by $I_{\mathrm{pc}} / I_{\mathrm{dc}}$, is seen to increase with increasing anodic current density and with decreasing crystallite size. This means that the photosensitivity increases with increasing porosity. Thus the effect is manifested because of the decrease in the dark current as an effect of the increase in the resistivity with increasing porosity. The constart photocurrent can be explained on the basis of the absorption coefficient of porous silicon. It has been reported (Zheng et al 1992) that the absorption coefficient of porous silicon is very small $\left(\sim 10^{3} \mathrm{~cm}^{-1}\right.$ at $\left.500 \mathrm{~nm}\right)$ on account of which even at $500 \mathrm{~nm}$ the penetration depth of light is over $10 \mu \mathrm{m}$. (The thickness of porous silicon layer was observed to be around $5-10 \mu \mathrm{m}$ from the surface.) As an effect, the photoconductivity observed in PS is mainly a contribution from the crystalline bulk which remains unaffected.

In the inset of figure 3 we have shown the photoconductivity of hydrogenated amorphous silicon ( $\mathrm{a}-\mathrm{Si}: \mathrm{H})$ synthesized by plasma chemical vapour deposition. It is seen that the behaviour of photoconductivity of PS can closely approach that of a-Si:H; with increasing porosity.

One of the surface properties, namely the work function, for PS samples of various crystallite sizes is shown in figure 4. The depth of the Fermi level from the vacuum level $(\phi)$ is plotted as a function of the anodic current density during the synthesis of PS, or in terms of the crystallite size as inferred from our XRD measurements. It is observed that $\phi$ increases as the crystallite size decreases and the porosity increases. 


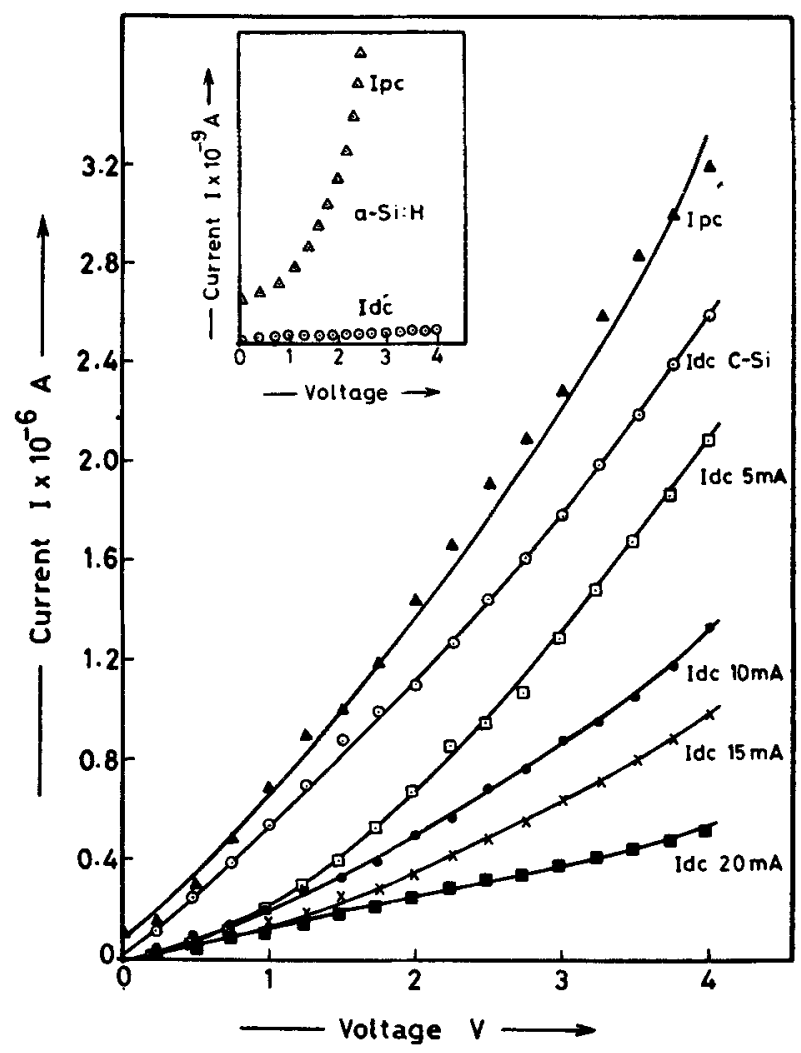

Figure 3. $I-V$ characteristics for porous silicon prepared with different anodic current densities. The photocurrent $\left(I_{\mathrm{pc}}\right)$ remained the same for all samples and dark current $\left(I_{\mathrm{dc}}\right)$ varied. The inset shows $I_{\mathrm{pc}}$ and $I_{\mathrm{dc}}$ for a-Si:H.

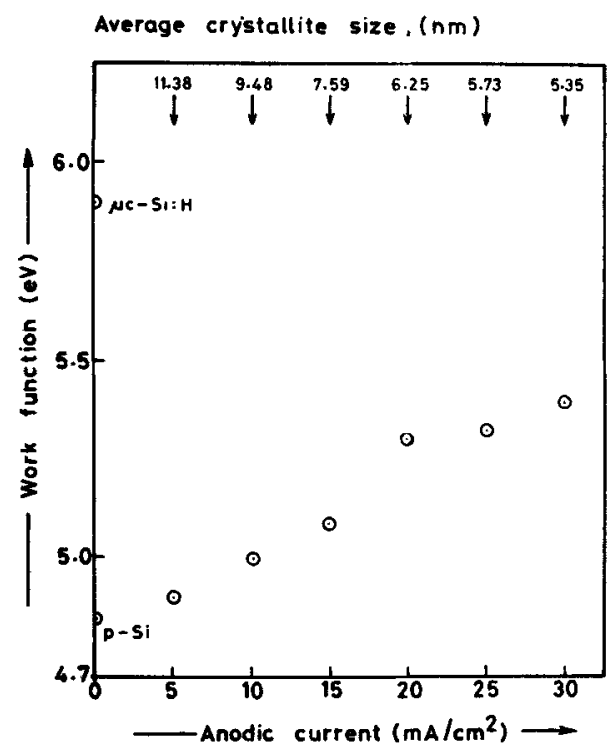

Figure 4. Work function measurements of porous silicon prepared with different anodic current densities. Respective crystallite sizes are also indicated. 
After preparing the samples of PS they were exposed to the ambient for about $48 \mathrm{~h}$. The increase in the work function may be due to an effect of the passivation of the pore surfaces with silicon oxide or silicon hydride type of complexes. With increasing concentration of pores the concentration of these complexes is expected to increase, thereby causing an increase in the value of the work function. These results show that the electronic property of the surface is modified with increase in porosity, although the peak position of the PL spectrum is unaffected.

The nature and extent of the surface states in PS was monitored from the thermally stimulated exoelectron emission (TSEE) spectra. Figure 5 shows a series of TSEE spectra for samples prepared with different anodic current densities. The nature of the spectra is compared with that of the crystalline p-silicon (111) surface, which is characterized by a broad peak centred around $300 \mathrm{~K}$, shown in figure $5 \mathrm{a}$. The number of peaks in a TSEE spectrum indicates the number of defect levels and their positions are indicative of their energies below the conduction band minimum. The general nature of the spectra $5 b, c$ show three broad peaks. It has been seen that with increasing porosity, the number of spikes have also increased. Figure $5 \mathrm{~b}$ shows a series of spikes

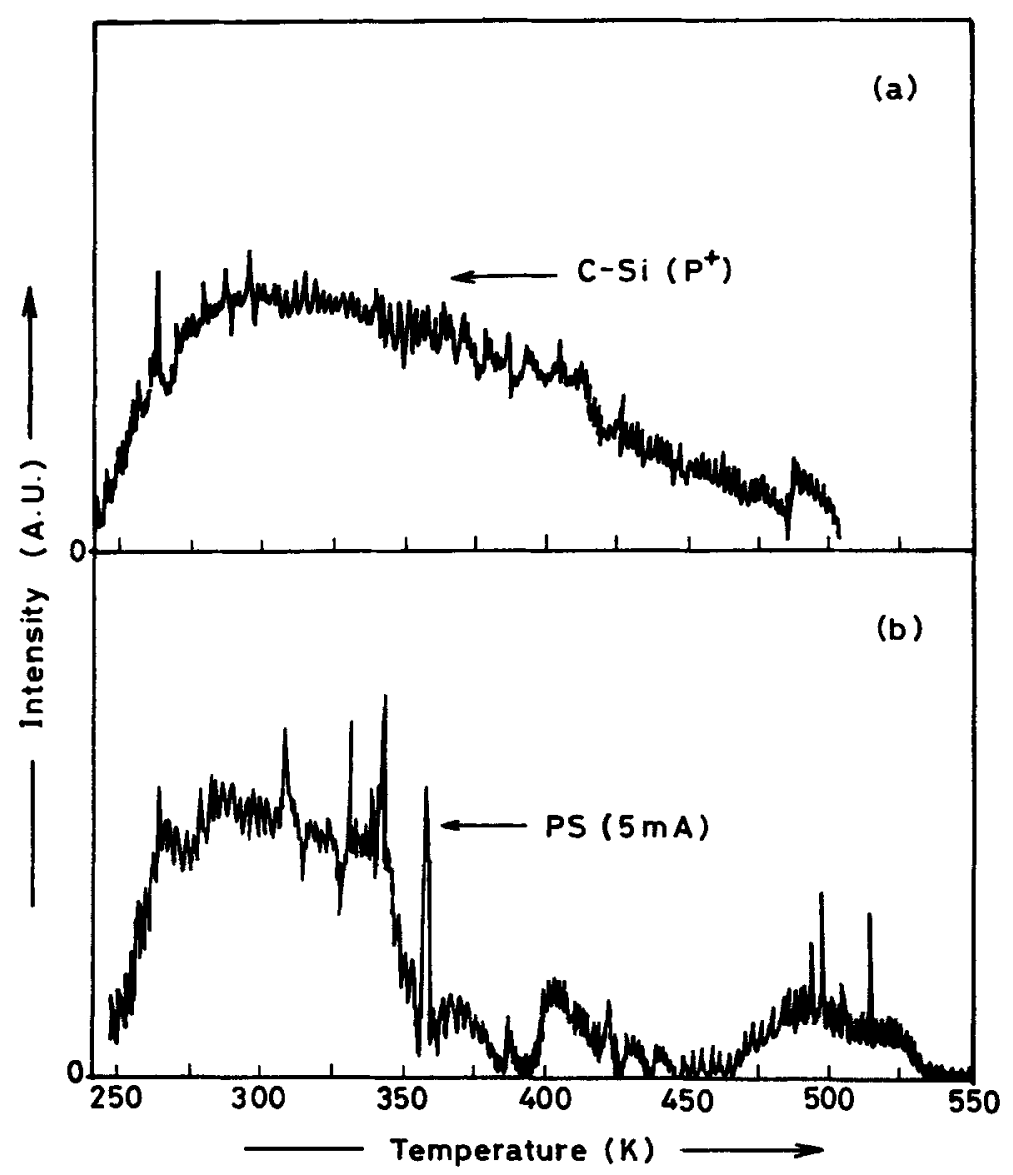

Figure 5. a-b. 


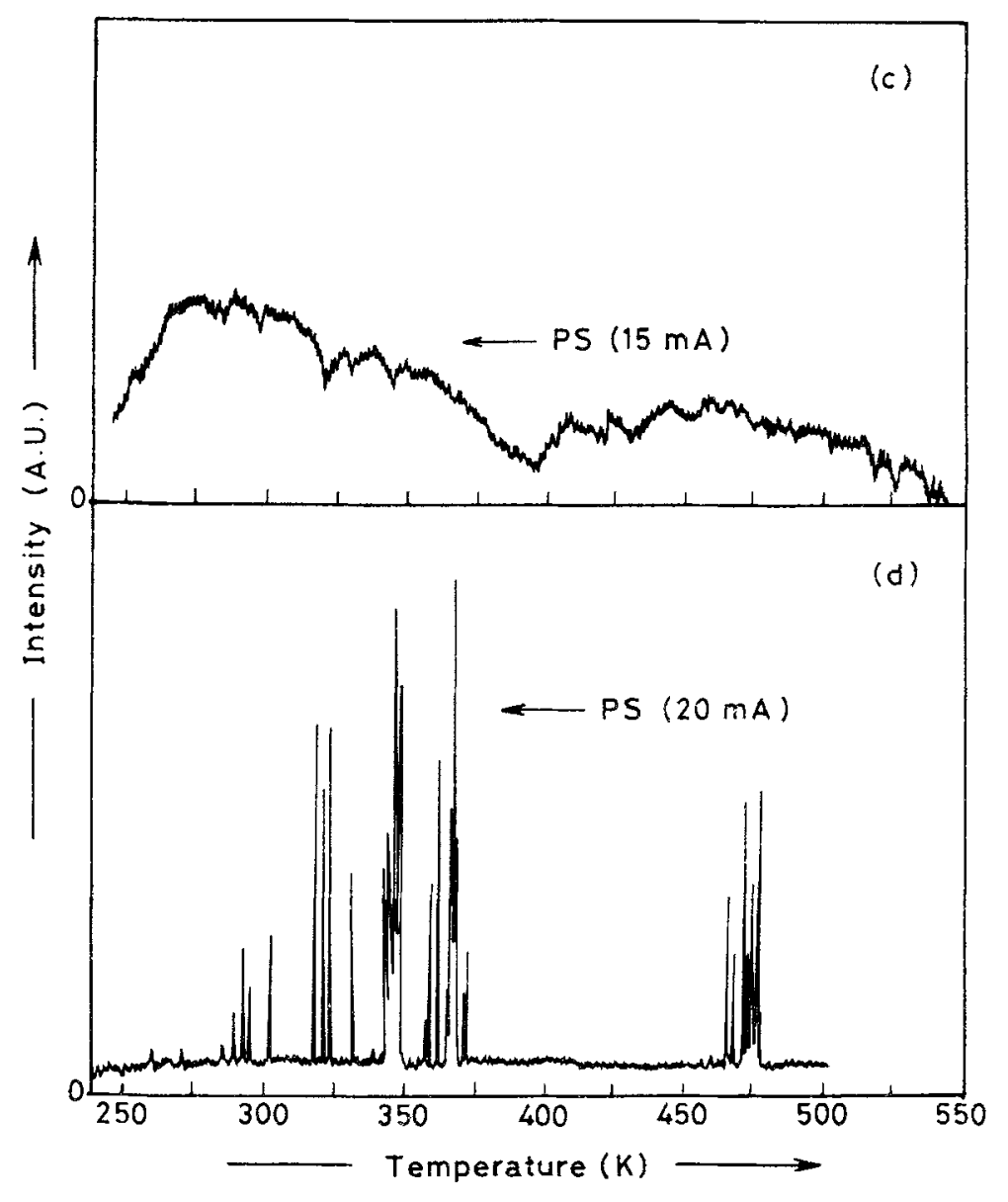

Figure 5. Thermally stimulated exoelectron emission spectra for (a) c-Si and (b to d) porous silicon samples prepared at different anodic current densities.

superimposed on the broad bump. This might be because of either (i) large surface potential caused by the surface states and effectiveiy leading to an extreme band bending resulting in tunnelling of conduction electrons at almost all the temperatures, or (ii) large number of discrete localized states at the surface of porous silicon.

Structural investigations using TEM were carried out with free-standing PS powder which exhibited PL as shown in figure 1 (curve a). Figure 6a shows a TEM inicrograph showing crystallite dimensions. Figure $6 \mathrm{~b}$ shows the electron diffraction pattern for a singie grain. The crystallite size was seen to be around $5 \ldots 10 \mathrm{~nm}$. The $d$ values were found to correlate with those of Si. The free-standing powder of PS is thus proved to only consist of crystallites of silicon. Moreover, the average particle size determined from TEM very closely resembles those determined from XRD measurements. It is therefore evident that the columns on the porous silicon consist of nanostructure crystalline silicon alone, however, terminated with oxygen and hydrogen bonds as is evident from our IR spectrum recorded with the free-standing puwder (figure $7 \mathrm{a}$ ) and compared with FTIR spectrum of PS prepared at $20 \mathrm{~mA} / \mathrm{cm}^{2}$ (figure $7 \mathrm{~b}$ ). 

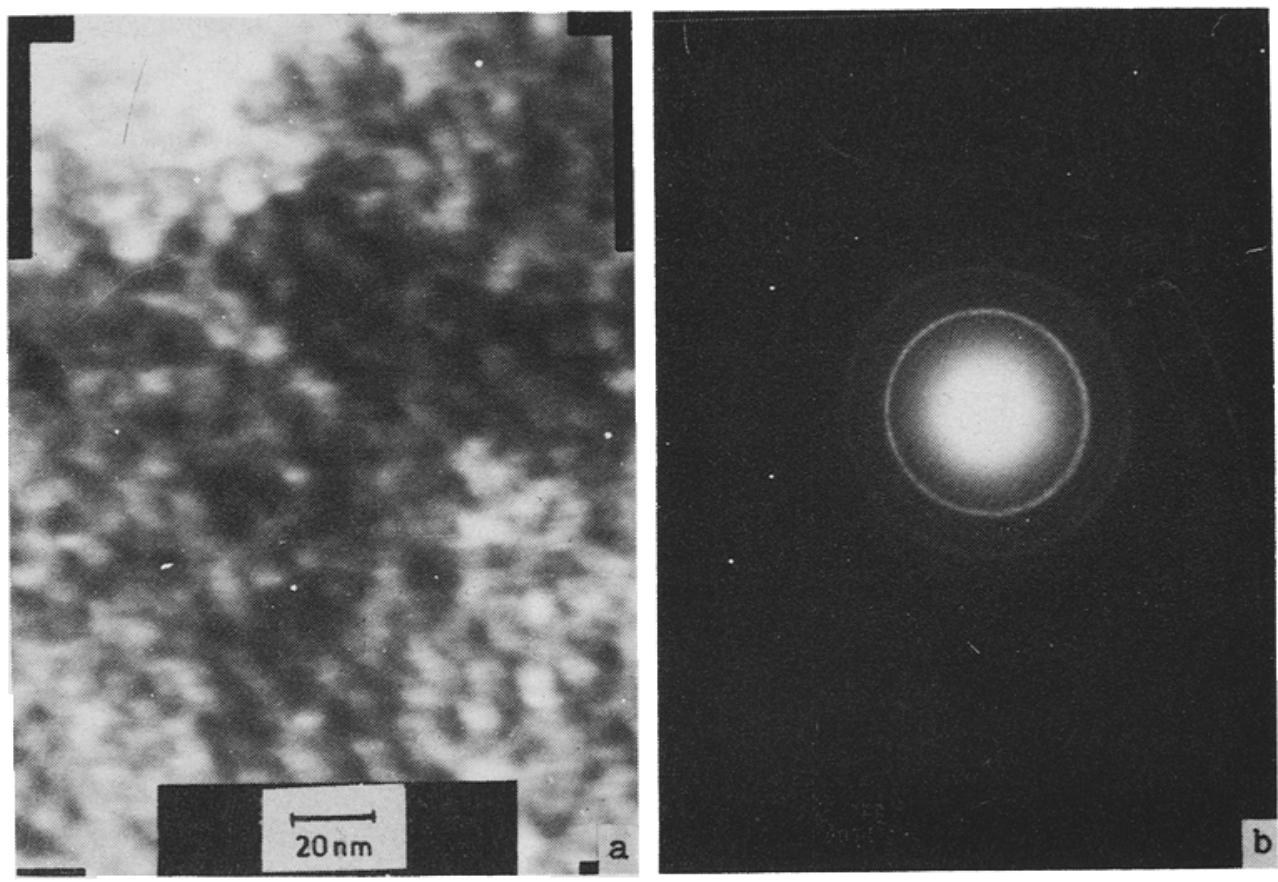

Figure 6. (a) TEM micrograph and (b) diffraction pattern of free-standing porous silicon powder.
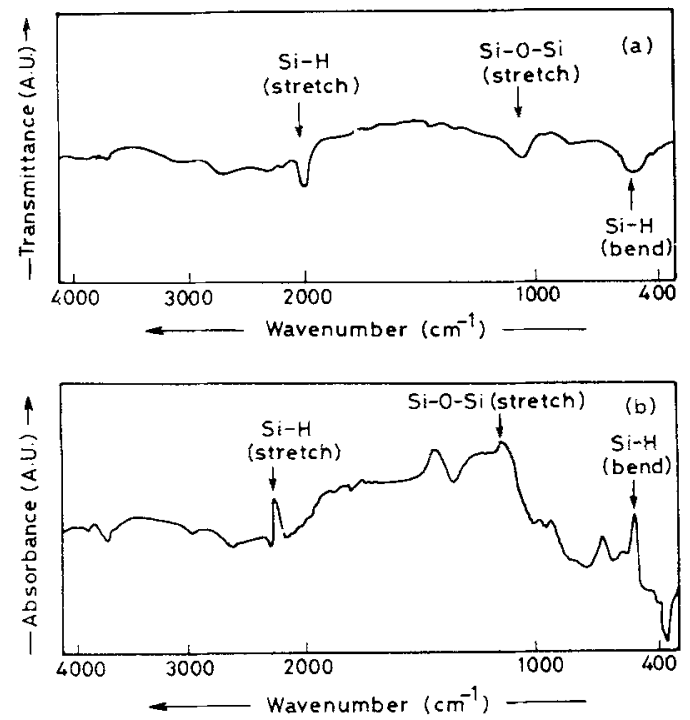

Figure 7. Infrared spectra of (a) free-standing porous silicon powder and (b) porous silicon prepared with anodic current of $20 \mathrm{~mA} / \mathrm{cm}^{2}$.

In conclusion we find that (i) nanocrystalline silicon structure is obtained by varying the anodic current density in the preparation of porous silicon, (ii) the photocurrent measurements show that with increasing the, current density the surface of silicon 
tends to approach that of hydrogenated amorphous silicon $(\mathrm{a}-\mathrm{Si}: \mathrm{H})$ film grown by plasma-assisted chemical vapour deposition, (iii) the work function measurements show that the nanocrystallites are embedded in a silicon complex of hydride and oxide-type species and (iv) the TSEE measurements show that with increasing current densities, surface states appear to be formed, which are continuously spread in energy inside the band gap. This may be arising from the $\mathrm{Si}: \mathrm{H}$ and $\mathrm{Si}-\mathrm{O}$ complexes appearing on the pore walls.

\section{Acknowledgements}

The authors express their sincere thanks to Dr S K Date and Dr Prabhat Singh, National Chemical Laboratory, Pune, for providing the experimental facilities for PL and TEM. TB is thankful to the Nuclear Science Centre, Delhi, for providing the fellowship. TAR cheerfully acknowledges the Council of Scientific and Industrial Research (CSIR), New Delhi, for fellowship.

\section{References}

Bellet D, Dolino G, Ligeon M, Blanc P and Krisch M 1992 J. Appl. Phys. 71145

Brandt M S, Fuchs H D. Stutzmann M, Weber J and Cardona M 1992 Solid State Commun. 81307

Canham L T 1990 Appl. Phys. Lett. 571046

Fathauer R W, George T. Ksendzov A and Vasquez R P 1992 Appl. Phys. Lett. 60995

Kanemitsa Y, Uto H and Masumoto Y 1993 Phys. Rev, B48 2827

Lehmann V and Gosele V 1991 Appl. Phys. Lett. 58856

Matsuda A. Kumagar K and Tanaka K 1983 Jpn. J. Appl. Phy's. 22 L34

Noguchi N and Sucmune I 1993 Appl. Phys. Lett. 621429

Ochiai Y, Ookvbo N, Watanabe H, Matsui S, Mochizoki Y, Ono H, Kimura S and Ichihashi T 1992 Jpn. J. Appl. Phys. 31560

Perez J M et al 1992 Appl. Phys. Lett. 61563

Prokes S M, Carlos W E and Bermudez V M 1992 Appl. Phys. Lett. 611447

Railkar T A, Bhide R S, Bhoraskar S V, Manorama V and Rao V J 1992 J. Appl. Phys. 72155

Rajopadhye N R and Bhoraskar S V 1986 J. Mater. Sci. Lett. 5603

Smith R I and Collins S D 1992 J. Appl. Phys. 71 R1

Stutzmann M, Brandt M S, Rosenbauer M, Weber J and Fuchs H D 1993 Phys. Rev. B47 4806

Tsu R, Shen H and Dutta M 1992 Appl. Phys. Lett. 60112

Vasquez R P, Fathauer R W, George T, Ksendzov A and Lin T L 1992 Appl. Phys. Lett. 601004

Xu Z Y, Gal M and Grass M 1992 Appl. Phys. Lett. 601375

Yon J J, Barla K, Herino R and Bomchill G 1987 J. Appl. Phys. 621042

Zheng J P, Jiao K L, Shen W P. Anderson W A and Kwok H S 1992 Appl. Phys. Lett. 64459 